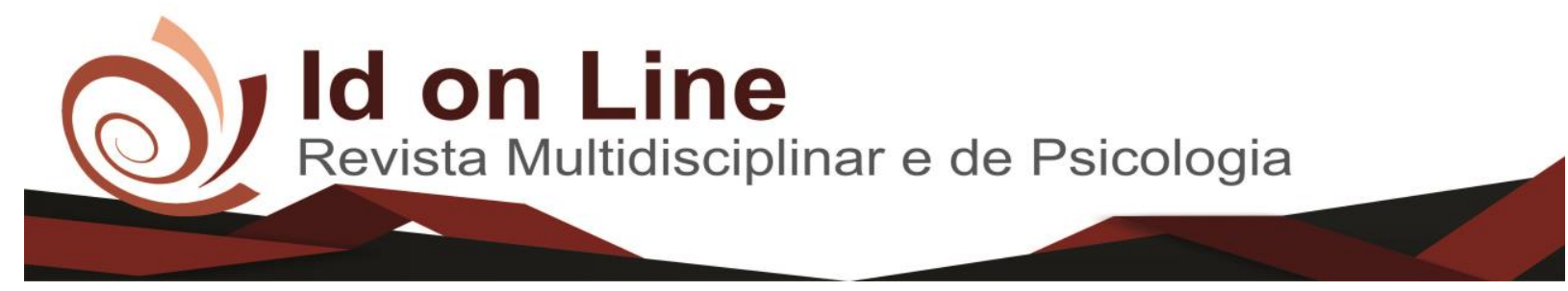

Artigo de Revisão

\title{
A Homofobia como Signo Ideológico dos Crimes de Ódio: Uma Análise da Argumentação Discursiva sobre os Direitos LGBT'S ${ }^{1}$
}

\author{
Miguel Ângelo Silva de Melo²; Isaac de Oliveira Magalhães e Silva \\ Karollyne Magalhães Dias ${ }^{4}$; Antoniel dos Santos Gomes Filho
}

Resumo: A justificativa da presente investigação se dá, por um lado, pela constatação de que nunca se teve um momento tão propício para se analisar os discursos homofóbicos proferidos por oradores que buscam propagar o ódio, intencionando assim, adesão aos seus discursos argumentativos por auditórios específicos. Por outro lado, encontramos a movimentação civil organizada LGBT que vêm na contramão destes discursos, promovendo a desconstrução da retórica-argumentativa do preconceito, da exclusão e da abjeção, trazendo perspectivas antihomofóbicas que se põem na transversalidade dos discursos do ódio, e respectivamente, buscam a criminalização dos crimes de ódio motivados pela orientação sexual e pela identidade de gênero da(s) vítima(s). A metodologia utilizada neste artigo é eminentemente, uma revisão bibliográfica de cunho sociológico com ênfase na produção da linguagem por meio de discursos argumentativos em defesa da dignidade da pessoa humana. Os achados indicam que a mobilização dos movimentos sociais foi fundamental para a definição de crimes de ódio enquanto todo e qualquer crime motivado pelo preconceito contra um determinado grupo social do qual a vítima faz parte direta ou indiretamente.

Palavras-chave: Discursos homofóbicos. Preconceito. Exclusão. Movimentos sociais. Criminalização.

\section{Homophobia as the Ideological Sign of Hate Crimes: An Analysis of Discursive Argumentation on LGBT Rights}

\begin{abstract}
The justification for the present investigation is given, on the one hand, by the fact that we never had such a propitious moment to analyze the homophobic discourses spoken by speakers who seek to propagate hatred, thus intending to adhere to their argumentative discourses by specific audiences. On the other hand, we find the organized civil movement LGBT that come against these discourses, promoting the deconstruction of
\end{abstract}

\footnotetext{
${ }^{1}$ Este artículo traz algumas discussões apresentadas na minha tese de doutorado em Sociologia de Miguel Melo, acrescentado de novas discussões advindas das reuniões do Laboratório Interdisciplinar de Estudos da Violência - LIEV. (This article brings some discussions presented in my doctoral thesis in Sociology of Miguel Melo, added of new discussions coming from the meetings of the Interdisciplinary Laboratory of Studies of the Violence - LIEV).

${ }^{2}$ Doutor em Sociologia pela Universidade Federal de Pernambuco. Docente do curso de Direito do Centro Universitário Doutor Leão Sampaio do (UNILEÃO). Docente do curso de Direito da Faculdade de Ciências Humanas do Sertão Central (FACHUSC). Pesquisador-líder do Laboratório de Estudos da Violência/ LIEV do Centro Universitário Doutor Leão Sampaio do (UNILEÃO). Licenciado em Pedagogia pela Faculdade Kurios (FAK) e Advogado de Direitos Humanos. E-mail: crioulo.miguelangelo.melo@ gmail.com.

3 Bacharel em Direito pelo Centro Universitário Dr. Leão Sampaio. Aluno especial do Programa de Pós-Graduação em Letras na Universidade do Estado do Rio Grande do Norte (UERN). Especializando em Docência do Ensino Superior pela Faculdade Kurius (FAK). Pesquisador Auxiliar do Laboratório Interdisciplinar de Estudos da Violência (Centro Universitário Dr. Leão Sampaio - Juazeiro do Norte, CE) na Linha de Pesquisa Etnofilosofia e Etnogênero. Pesquisadora na área de gênero, religiões e religiosidades, com ênfase em análise de discurso. E-mail: Isaacmoliver@hotmail.com.

${ }^{4}$ Especialista em Psicopedagogia Institucional e Clínica pela Faculdade Kurios (FAK). Licenciatura em Pedagogia pela Faculdade Kurios (FAK). Aluna especial do Programa de Pós-Graduação em Letras na Universidade do Estado do Rio Grande do Norte (UERN). Pesquisadora Auxiliar do Laboratório Interdisciplinar de Estudos da Violência (Centro Universitário Dr. Leão Sampaio - Juazeiro do Norte, CE) na Linha de Pesquisa Educação Brasileira e Internacional. Pesquisadora na área de religiões e religiosidades, com ênfase em análise de discurso. Email: kkaroldias@ hotmail.com.

${ }^{5}$ Professor do curso de Administração da Faculdade Vale do Salgado (FVS). Mestre em Educação Brasileira pela Universidade Federal do Ceará (UFC). Pesquisador do Laboratório Interdisciplinar em Estudos da Violência no Centro Universitário Dr. Leão Sampaio (LIEVUNILEÃO), do Grupo de História e Educação Comparada no Programa de Pós-graduação em Educação da UFC. Tecnólogo em Gestão Comercial pela UNILEÃO. Discente de Licenciatura em Filosofia na Faculdade Católica de Fortaleza (FCF). E-mail: antoniel.historiacomparada@gmail.com
} 
the rhetoric-argumentative of prejudice, exclusion and abjection, bringing anti-homophobic perspectives that are put in the transversality of the speeches of hate, and respectively, seek the criminalization of hate crimes motivated by the sexual orientation and gender identity of the victim (s). The methodology used in this article is eminently a sociological bibliographical revision with emphasis on the production of language through argumentative discourses in defense of the dignity of the human person. The findings indicate that the mobilization of social movements was fundamental for the definition of hate crimes while any crime motivated by prejudice against a particular social group of which the victim is a direct or indirect part.

Keywords: Homophobic discourses. Preconception. Exclusion. Social movements. Criminalization.

\section{Considerações iniciais}

A justificativa da presente investigação se dá, por um lado, pela constatação de que nunca se teve um momento tão propício para se analisar os discursos homofóbicos proferidos por oradores que buscam propagar o ódio, intencionando assim, adesão aos seus discursos argumentativos por auditórios específicos. Por outro lado, encontramos a movimentação civil organizada LGBT que vêm na contramão destes discursos, promovendo a desconstrução da retórica-argumentativa do preconceito, da exclusão e da abjeção, trazendo perspectivas antihomofóbicas que se põem na transversalidade dos discursos do ódio, e respectivamente, buscam a criminalização dos crimes de ódio motivados pela orientação sexual e pela identidade de gênero da(s) vítima(s).

O presente artigo se propõe a refletir sobre a atualidade brasileira, principalmente, diante da sensível e majorante situação de violência motivada pela LGBTfobia que o país se encontra, uma vez que nos Estados brasileiros nunca se observou tanta brutalidade e torpeza nos crimes homofóbicos motivados pela orientação sexual e identidade de gênero não heterossexual como no hodierno. Constatam-se fatores externos presentes no sistema de justiça criminal que, além de dificultarem o desenvolvimento de plataformas de afirmação dos direitos de cidadania, pelo controle da criminalidade violenta, são incapazes de promover uma justiça criminal sólida e eficaz - que não apenas garanta a manutenção da ordem pública, mas que também previna e combata a insegurança e a propagação de hostilidades que findam por incentivar a violência homofóbica no Brasil, como por exemplo, os discursos argumentativos proferidos por oradores do Legislativo em relação a homossexualidade (bissexualidade, travestilidade, transexualidade, entre outras formas de orientação sexual e identidade de 
gênero). Somam-se a estes fatores, grandes empecilhos organizacionais e burocráticos, que compactuam para a propagação do sentimento de insegurança (inércia e descaso do sistema de justiça criminal) legitimado pelo Estado no dia a dia das suas relações sociais com os grupos vulneráveis em específico.

Neste sentido, Miguel Melo (2017) ressalta que os homicídios homofóbicos, assim como a homofobia, em suas distintas formas, não têm sido muito estudados pelas ciências sociais e jurídicas, principalmente, em virtude das realidades de preconceito e hostilização para com o tema, conforme observou o autor em sua inserção a campo. Assim, navegando em águas turbulentas, recheadas pelo ódio e pelo preconceito, ao se iniciar a revisão de literatura, muitos problemas foram se elucidando até que ficasse totalmente expresso que grandes avanços em matéria de gênero foram realizadas e aconteceram no Estado brasileiro, principalmente, na última década. Todavia, apesar de todas as conquistas, infelizmente, muitos paradigmas teóricos ainda tentam "patologizar" ou "tratar" as sexualidades humanas que deslizem ao padrão da heterossexualidade (heterossexualidade compulsória).

Frente ao exposto, vale destacar que o propósito do presente estudo se centra, por um lado, em analisar a importância que a argumentação militante e ativista teve e ainda tem na consagração de discursos argumentativos em defesa da diversidade sexual; por outro lado, busca-se observar como estes vêm influenciando a judicialização e o espraiamento de leis que salvaguardem a nova retórica em torno dos Direitos Humanos. A metodologia utilizada neste artigo é eminentemente, uma revisão bibliográfica de cunho sociológico com ênfase na produção da linguagem por meio de discursos argumentativos em defesa da dignidade da pessoa humana.

\section{Os Discursos da Trajetória e da Politização da Identidade Homossexual}

Na segunda metade do século XX, mais especificamente, entre a década de sessenta e setenta, ocorreram importantes movimentações político-ideológicas na Europa Ocidental e nos Estados Unidos, chamados de "novos movimentos sociais", que foram fundamentais para diversas transformações tanto nas sociedades locais, como na sociedade mundial. Nos EUA, esses novos movimentos iniciaram-se com o movimento por direitos civis dos negros que buscavam, através do ativismo político e da militância "crítico-conspirativa” (SILVA, 2011), 
promover mudanças significativas nas estruturas do American way of life. Este establishment era, acima de tudo, homogeneizador e indicador de posições-de-sujeitos que eram coagidos pelas normas - culturais sociais e religiosas - que impunham relações assimétricas e classificações hierarquizantes estabelecendo dicotomias entre "Nós" (homens brancos, de classe média, cristãos, heterossexuais) e "Eles" (homens e mulheres de cor, trabalhadores, não cristãos e não heterossexuais). (BERUTTI, 2010).

Esses movimentos sociais foram acusados de promover separações, de ir de encontro às ações estatais, de desestabilizar normalizações e de desobedecer às estruturas homogeneizadoras da ordem social, ao buscarem corromper e subverter as identidades "normais" e "fixas" proporcionadoras da ordem capitalista. Essas ideias, além de desarticularem os paradigmas da modernidade, em distintos e diferentes nuances, mobilizamse e desmobilizam-se em territórios, imigrando e emigrando, num eterno "cruzado de fronteiras", que objetiva corromper identidades. Assim, fazem morada nos países centrais da Europa Ocidental e América do Norte, até chegarem aos países do chamado "Sul Global" (sociedades periféricas). (SANTOS, 2008).

John Franklin e Alfred Moss Jr. (1999) caracterizam a história de exclusão étnicoracial e a conquista dos direitos civis do povo afroamericano como uma história de exclusão, de apoderamento, de libertação e, em alguns momentos, de união com outros movimentos de contestação. Os autores mostram a importância da revolução negra, as marchas pela liberdade, os desafios da igualdade, a importância do ativismo, as dinâmicas econômicas e políticas que proporcionaram a efetivação dos direitos em tempos de turbulência, que serviram de fundamento ideológico para outros movimentos sociais. Segundo Jeffrey Weeks (1994), o movimento étnico-racial afroamericano é reconhecido tanto pelo ativismo político, quanto pela literatura científica como o movimento pioneiro, tanto na produção de uma emancipação política, como também na formação de uma identidade cultural de sujeitos marginalizados e oprimidos ao longo da história dos Estados Unidos.

Neste sentido, Kathryn Woodward (2011) acrescenta que estes novos movimentos sociais teriam sido responsáveis pela postura política de desacordo tanto com as regras, como com o "establishment e suas hierarquias burocráticas" (Ibid., 2011, p. 34). Esta grande movimentação fez com que muitos militantes negros e brancos - proativos simpatizantes defensores do movimento negro acreditassem na transformação do comportamento e da tolerância étnico-racial pudesse ser complemente reestabelecida. (RÄTHZEL, 1997). Por 
outro lado, era necessário destruir ou “ (des-)significar” as estratégias fixas e homogeneizantes promovedoras da diferença, como ressalta Hall (2003), ao criticar a proliferação das diferenças e o domínio destas sobre o poder cultural, acrescenta que este, da mesma forma que é econômico, também é um poder tecnológico, principalmente, quando ressalta que a luta pelo poder "parece estar sempre marcado e compensado por conexões laterais, que produz uma visão de mundo composta de muitas diferenças locais”. (HALL, 2003, p. 60).

Sob a perspectiva do intenso ativismo e litigância política promovida pela movimentação afro americana, outros movimentos sociais tomaram corpo social, ao perceberem as vantagens e as possibilidades de mudança dadas com a contestação já realizada ao establishment norte-americano. Abrindo portas e quebrando fronteiras para a emancipação política e à promoção de novas identidades subalternas e transgressoras à ordem social machista e heterossexista, como aconteceu com a segunda onda do movimento feminista, como com o movimento homossexual, que tomaram formas e foram aos campos de batalha na luta pela efetivação de seus direitos. (BERUTTI, 2010; SILVA, 2011).

Em consonância com esta retrospectiva histórica, Tomaz Tadeu Silva (2011) afirma que esse contexto de ativismo, originado pelos novos movimentos sociais, ressaltava a importância da teoria cultural e de suas reflexões pós-estruturalistas, na interpretação e no desenvolvimento de novas identidades, antes percebidas como fixas, universais e indivisíveis, gerando uma mudança na concepção dos sujeitos, que deixavam de ser vistos como sujeitos de identidade concreta. Para o autor, a ideologia que produz tanto a identidade quanto a diferença é oriunda de processos imaginários que negam a existência da mobilidade e da (des)territorialidade, principalmente se estas ideias que estão em constante movimento, negarem as concepções de hegemonia e de manutenção do poder antes atribuído aos grupos dominantes e atribuidores da identidade.

Em adição, percebe-se que a "des-fixação", a "ressignificação" ou a "remodelação" das concepções de sujeito permitiram que se desenvolvessem novas concepções na política de gênero, uma vez que "o próprio sujeito das mulheres não é mais compreendido em termos estáveis ou permanentes. [...] as qualificações do ser sujeito têm que ser atendidas para que a representação possa ser expandida". (BUTLER, 2008, p.18). A partir da crítica da autora, os sujeitos de gênero seriam determinados por políticas de dominação que, compulsoriamente, estabeleciam, por um lado, estruturas hierárquicas entre os gêneros; e, por outro lado, a 
identificação da matriz sexo-gênero-desejo com os ideais do masculino (heteronormatizado). Neste contexto, de transformações e acirrados debates, em torno das tecnologias do gênero, Teresa de Laurentis (1987), acrescenta que:

\begin{abstract}
Nos escritos feministas e nas práticas culturais dos anos 60 e 70, o conceito de gênero como diferença sexual encontrava-se no centro da crítica da representação, da releitura de imagens e narrativas culturais, do questionamento de teorias de subjetividade e textualidade, de leitura, escrita e audiência. O conceito de gênero como diferença sexual tem servido de base e sustentação para as intervenções feministas na arena do conhecimento formal e abstrato, nas epistemologias e campos cognitivos definidos pelas ciências físicas e sociais e pelas ciências humanas ou humanidades [...]. Mas o conceito de gênero como diferença sexual e seus derivados - a cultura da mulher, a maternidade, a escrita feminina, a feminilidade etc. acabaram por se tornar uma limitação, como uma deficiência do pensamento feminista. (IBID., 1987, p. 1)
\end{abstract}

Por certo, corroboramos com a crítica da autora, principalmente quando esta constata a existência de uma equação de legalidade e legitimidade em relação aos sujeitos por parte das estruturas políticas e jurídicas e suas derivadas ações governamentais, visto que estas, direta e indiretamente, inibem a visibilidade política e impedem os processos de efetivação de direitos destes sujeitos (SILVA, 2000). Não restam dúvidas de que as contribuições da resistência pela militância política e científica LGBT, advindas das últimas décadas do século XX, foram substanciais para elevar os padrões de subjetividade, contribuindo com a emancipação política e jurídica e com a compreensão de que a categoria de gênero estava sendo percebida como uma "grande performance ideológica naturalizada pela exploração que privilegia o heteromasculino". (SANTOS, 2014., p. 70). Verifica-se que esse processo, da mesma forma que aconteceu com o movimento negro e com o movimento feminista, repetiu-se dentro do movimento homossexual. Desenvolveu-se nesse movimento um cunho revolucionário pela insistência na fomentação de novas práxis, capaz de transformar a realidade pela visibilidade de novas frentes de luta contra o preconceito, a exclusão, a discriminação e a heressexualidade compulsória (lógica heterofalocêntrica).

Neste contexto, foi que se deu a aproximação entre o movimento homossexual com o movimento feminista, e mais especificamente como o movimento feminista lésbico, mesmo que esta aproximação seja permeada por tensões e conflitos. (BÖS, 2005; BOYLE, 2001). No que diz respeito à trajetória do movimento homossexual brasileiro, é importante categorizar que, da mesma forma como aconteceu nos EUA e nos países centrais da Europa Ocidental, as experiências dos pioneiros grupos de militância LGBT no Brasil, até a virada do século XX, 
foram marcadas por episódios de violência, segregação, higienização, perseguição, medo e ativismo nas suas mais derivadas formas de atuação, posto que a perseguição vinha de todos os lados, ou seja, ela era social, cultural e estatal (órgãos de controle e de segurança pública), bem como pela ciência e pela igreja. Ou seja, o pioneiro movimento homossexual brasileiro (MHB) e seus sujeitos estavam cercados de "inimigos" e de estigmas - tais como: "invertidos sexuais", "loucos", “pervertidos", “doentes", "imorais", “pecadores” entre outros rótulos - por todos os lados. (MOTT, 1987; 1986; TREVISAN, 1986; MACRAE, 1983) .

Entre meados da década de setenta e inícios da década de oitenta, os novos movimentos sociais "pró-democracia" começam a se organizar e estruturar no Brasil pósabertura política; com o retorno dos exilados políticos dos mais diferentes movimentos de contestação social, o MHB começa a dar seus primeiros "sinais de vida" com a chegada de lideranças LGBT que haviam deixado o país, muito embora existisse, desde década de setenta, alguma movimentação política, como o trabalho de Celso Curi no Jornal "A Última Hora", editor da chamada "Coluna do Meio" que, em 1975, já dava sinais da existência de uma movimentação homossexual no Brasil. Muito embora, apenas o início da década de oitenta é que marca oficialmente a organização política dos movimentos sociais (homossexual) no Brasil.

Neste sentido, tanto Spagnol (1996) quanto Brayner (1998) e Silva (1998) atribuem semelhante cronologia, ao afirmarem tacitamente que, em abril de 1978, é editado e publicado o primeiro jornal homossexual brasileiro, chamado Lampião da Esquina, que existiu até 1981, que tinha uma média de tiragem de cerca de 10.000 exemplares por mês. O jornal seguia o modelo crítico da Gay Liberation e da Lesbian Feminism, apesar de apresentar peculiaridades genuínas da cultura brasileira, muito embora tivesse como fulcro promover avaliações e discussões críticas sobre a homossexualidade, a exclusão social e para uma "des-guetificação" da comunidade LGBT brasileira:

Lampião aparece no cenário brasileiro como a primeira revista de contestação homossexual, fomentando, inclusive a criação de vários grupos de ativismo gay no cenário nacional. Pela primeira vez se estabelece no país uma cobertura feita pela imprensa alternativa abordando o tema do homossexualismo numa linha de crítica aos modelos sociais que agem de forma repressiva e preconceituosa em relação aos

\footnotetext{
${ }^{6}$ Antônio Spagnol (1996) e Aquiles Brayner (1998) creditam ao pioneiro trabalho do sociólogo José Barbosa da Silva (1959), sobre as vivências dos homossexuais em contextos de marginalidade e prostituição na região central da grande São Paulo, o reconhecimento de seu estudo como a primeira investigação nacional sobre o comportamento de homossexuais no Brasil.
} 
gays. [...]. O modelo seguido pelos redatores da revista, no sentido de trabalhar a quebra dos tabus relacionados à opção homossexual, segue a linha de atuação dos grupos de homossexuais atuantes nos Estados Unidos. (BRAYNER, 1998, p. 23).

Assim, na esteira das discussões do Lampião, surgem alguns estudos acadêmicos, como também eclodem, em muitas capitais brasileiras, a criação de grupos de ação pelos direitos civis, por emancipação homossexual e pelo desejo de afirmar uma identidade, como aponta Guacira Louro, ao indicar a este respeito que a "afirmação da identidade supunha demarcar suas fronteiras e implicava numa disputa quanto às formas de representá-la". (IBID., 2001, p. 543).

Neste sentido, Regina Facchini (2005) aponta que o "SOMOS - Grupo de Afirmação Homossexual" teria sido "o primeiro grupo reconhecido na biografia como tendo uma proposta de politização da questão da homossexualidade” (IBID., p. 93). Posteriormente, segundo a autora, seguiram-se ao SOMOS (SP e no RJ) outros grupos pioneiros, tais como: o Grupo Lésbico-feminista, o Grupo de Ação Lésbico-Feminista (GALF), o Outra Coisa, o Grupo Gay da Bahia, Grupo Atobá - Momento de Emancipação Homossexual, Grupo de Resistência Asa Branca (GRAB) entre outros grupos que surgiram os passos do SOMOS, a partir de 1978, na luta contra o preconceito.

Melo (2001) aponta outros fatores, ao longo dos anos, contribuíram para que, de alguns grupos, fossem dissolvidos, muitos novos surgissem, apesar de que poucos grupos de outrora permanecessem até os dias de hoje. Por certo, um exemplo destes problemas se deu a partir da disputa terminológica - entre os termos "bicha" e "gay" - que gerou grande discussão, haja vista que a criação de um termo nacional "bicha" deveria identificar o homossexual masculino em contraposição à influência do termo "gay", generalizado pelo ativismo norte-americano e que, para muitos ativistas, não deveria ser usado no Brasil. (MOTT, 1987; MACRAE, 1983) ${ }^{7}$. Dentro desta perspectiva, Peter Fry e Edward MacRae (1988) enfatizam que um dos primeiros posicionamentos da militância homossexual brasileira foi a tentativa de criar um termo genuinamente nacional. Por conta disso, o termo "bicha" era

\footnotetext{
${ }^{7}$ Dentro desta perspectiva, Peter Fry e Edward MacRae (1988) enfatizam que um dos primeiros posicionamentos da militância homossexual brasileira foi a tentativa de criar um termo genuinamente nacional. Por conta disso, o termo "bicha" era um termo comum em todo o território nacional, mesmo que tivesse um sentido pejorativo e, de certo modo, depreciativo, por isso sofria resistência de alguns ativistas, que optavam pelo termo gay, na busca da criação de uma identidade homossexual masculina. Apesar de que tenha sido feito opção pelo termo "bicha", em um primeiro momento, década de setenta e inícios de oitenta, este termo foi, posteriormente, substituído pelo termo gay, que se mantêm até hoje. (CARRARA, 2010).
} 
um termo comum em todo o território nacional, mesmo que tivesse um sentido pejorativo e, de certo modo, depreciativo, por isso sofria resistência de alguns ativistas, que optavam pelo termo gay, na busca da criação de uma identidade homossexual masculina. Apesar de que tenha sido feito opção pelo termo "bicha", em um primeiro momento, década de setenta e inícios de oitenta, este termo foi, posteriormente, substituído pelo termo gay, que se mantêm até hoje. (CARRARA, 2010).

No que concerne a isto, Melo (2001) e Facchini (2003; 2005) apontam que a década de oitenta, para o MHB, é marcada pela tentativa de reorganização dos grupos de emancipação e não oficialmente de emancipação homossexual em virtude AIDS, assim, nascem novas ONGs, assim como surge a estratégia da assistência em conjunto com a militância, dentre os quais se pode citar: os Grupos de Apoio e Prevenção à AIDS (GAPA's - 1985), o Grupo Atobá (1985), a Associação Brasileira Interdisciplinar de AIDS (ABIA - 1986) e os Grupos Pela Vidda (Pela Valorização, Integração e Dignidade do Doente de Aids - 1989), como também o "início" do reconhecimento dos grupos de emancipação homossexual, a exemplo do GGB e do Triângulo Rosa, de modo respectivo, pelas Câmaras Municipais de Salvador e Rio de Janeiro como Grupos de Utilidade Pública. Logo depois, o mesmo acontece com o Dialogay (Sergipe) e com o GRAB (Ceará) entre outros grupos.

A década de noventa é marcada novamente pela tentativa de fortalecimento e articulação dos grupos de emancipação LGBT no Brasil, quando aconteceu em Recife, de 7 a 13 de janeiro de 1991, em virtude da desarticulação dos grupos homossexuais no Sul e Sudeste, o V. Encontro Brasileiro de Homossexuais, o qual contou com a presença de seis grupos, como no evento anterior. Assim, mais uma vez o Nordeste sedia mais um encontro nacional, já que o IV EBHO também havia acontecido no Nordeste, na cidade de Aracajú/SE (de 11 a 14 de janeiro de 1990). Os temas tratados no V Encontro discutiam entre outros: a) as teorias sobre a homossexualidade; b) a religião e a repressão à homossexualidade; c) a organização e o fortalecimento do MHB, bem como, o incentivo e a organização de novos grupos; d) o abandono do gueto e o fortalecimento de uma identidade homossexual; e) o enfrentamento e a majoração de agendas públicas na luta contra a AIDS. (MELO, 2001; FACCHINI, 2003).

À tona da reorganização LGBT, ocorre em Curitiba/PR, janeiro 1995, o VIII EBHO, ocasião em que foi fundada a Associação Brasileira de Gays, Lésbicas, Transexuais e 
Travestis. De acordo com Melo (2001) e GGB (2001) ${ }^{8}$, participaram deste encontro 16 (dezesseis) grupos do Nordeste, 3 (três) da região Norte; 5 (cinco) da região Centro-Oeste; 6 (seis) do Sul; e 18 (dezoito) da Região Sudeste. Por conseguinte, desde sua fundação em Curitiba, a ABGLT, depois, transformada em ALGBT, nasce como uma sociedade civil organizada motivada para representar os interesses civis, sociais, políticos e culturais de lésbicas, gays, bissexuais, travestis e transexuais brasileiros, surgida de assembleia pública que contou com a presença de mais de (50) cinquenta grupos de emancipação LGBT das cinco diferentes regiões do país ${ }^{9}$. Com certeza, destaca-se a importância dos trabalhos desenvolvidos pela ABLGBT, como também de todos os grupos que compõem o cenário político-militante do atual movimento nacional, os quais, no que lhe concerne, passaram juntamente com a gestão pública - Federal e Estadual - a desenvolver e promover agendas públicas voltadas à comunidade LGBT, desde o Governo de Luiz Inácio Lula da Silva, como, por exemplo, as ações afirmativas que, desde maio de 2004, passaram a levar a rubrica "Brasil Sem Homofobia: Programa de Combate à Violência e à Discriminação contra LGBT e de Promoção da Cidadania Homossexual”. (CARRARA, 2010).

\section{As Vozes dos Direitos Humanos Sobre os Crimes de Ódio e da Homofobia}

Em inícios da década de oitenta do século XX, a terminologia crime de ódio ("hate crime") surge nos EUA, como um problema social - a ser estudado, discutido e solucionado. Rios (2007) ressalta que "o elenco do antissemitismo, do racismo, do sexismo e, mais ultimamente, da homofobia como casos emblemáticos da discriminação" (IBID., p. 47) tornaram-se objetos da literatura especializada, preocupada em conhecer e prevenir os casos de discriminação direta e indireta nestas sociedades. Levin e Mcdevitt (2008) e Berson (1996) apontam que, desde inícios da década de oitenta, o tema dos crimes de ódio ganha visibilidade com a explosão dos novos movimentos sociais que, além de exigirem a institucionalização do debate em torno dos crimes de ódio, por parte do Estado - com a adoção de agendas de

\footnotetext{
${ }^{8}$ Neste sentido, ver GGB. Disponível em: http://www.ggb.org.br/grupgays_s.htm. Acesso em: 03.05.2001.

${ }^{9}$ Lembrando que, na sua formação inicial, ainda enquanto ABGLT, teve a participação de 4 (quatro) grupos exclusivamente lésbicos, 4 (quatro) grupos apenas de travestis, 1 (um) grupo tão-somente de transexuais, 1 grupo exclusivamente de bissexuais e, o restante dos grupos majoritariamente gays ou mistos, muito embora, fossem, predominantemente, formados por gays.
} 
combate tanto as formas de discriminação existentes, quanto ao desenvolvimento de políticas de enfrentamento - levantam a crítica epistemológica e social sobre a necessidade de enfrentamento e de torná-los um problema social e objeto de estudo das ciências sociais, jurídicas e políticas de saúde e de segurança pública:

\begin{abstract}
O termo "crime de ódio" apareceu pela primeira vez no final dos anos 80 como forma de resposta ao incidente que ocorreu na praia de Howard, proximidades da cidade de New York, quando um homem negro foi morto ao tentar escapar de um grupo de adolescentes violentos que gritavam epítetos raciais. Embora amplamente utilizado pelo governo Federal dos Estados Unidos, bem como, pela mídia e pelos pesquisadores na área, o termo é um pouco contraditório, porque sugere incorretamente que o ódio é invariavelmente uma característica distintiva desse tipo de crime. (LEVIN; MCDEVITT, 2008, p. 102).
\end{abstract}

Essas novas dinâmicas promovidas pelo ativismo social e acadêmico, ao fragmentar a produção do conhecimento clássico e opressor, a partir do momento em que estes buscaram a superação das totalidades discursivas, homogêneas e excludentes, que sustentavam e legitimavam a lógica da discriminação (SANTOS, 2002). Neste sentido, ressaltam Levin e McDevitt (1993) que existem três tipos de agressores de ódio, que podem ser distinguidos a partir do proposto esquema: a) o agressor repressor (reactive offenders) - Geralmente é uma pessoa adulta, que tem receio de perder o seu trabalho e da ameaça da perca de privilégios oriundos do seu trabalho ou atividade que realiza, por isso, a sua ação é uma menção comunicativa pela violência à pessoa ou grupo que o ameaça. Age motivado pelo egoísmo, geralmente etnocêntrico, acreditando que sua verdade por si basta. Dificilmente age em grupo, salvo exceções, quando toda a coletividade estiver sofrendo ameaça de outro coletivo que é um inimigo comum a todos; b) o agressor "fazedor de emoções" (thrill-seeking offenders) inserir o termo em inglês, em itálico) - Geralmente é mais jovem que o agressor relativo, por isso ainda não está profissionalmente e socialmente estabilizado. Devido à sua pouca idade, não é capaz de ser formador de opiniões ou influenciador de indivíduos, a não ser os que fazem parte de seu grupo (sub-) cultural. Exatamente por isso precisa do reconhecimento de seus pares ${ }^{10}$; c) o agressor da missão moral (mission offenders) - Defensores de uma moralidade inquestionável que é legitimada por específicas razões (morais, religiosas,

\footnotetext{
10 Age sem pensar por emoções externas, é facilmente manipulável, e uma arma para agir motivado quando liderado por relações e poder e dominação (política, economia, religião, sexual, tradição e cultura). Acredita que sua ação é boa em si e per si. Assim, alcançara o reconhecimento social, a partir do momento em que sua ação será legitimada tanto pela sociedade (comunidade) como pelo Estado, povo ou grupo religioso.
} 
culturais e político-ideológicas) para livrar o mundo (a sociedade, a comunidade, o Estado) da presença e existência dos inimigos - estranhos, pagãos, hereges, pecadores etc. -, contraventores da paz e da ordem social, ou seja, por difundirem o bem, devem exterminar o mal (aqueles por ele representados) da sociedade mundial.

A mobilização dos movimentos sociais foi fundamental para a definição de crimes de ódio ${ }^{11}$ enquanto todo e qualquer crime motivado pelo preconceito contra um determinado grupo social do qual a vítima faz parte direta ou indiretamente. (ROSENFELD, 2003). Decerto, os crimes de ódio surgem de ações e práticas diversas motivadas pelo fato de que o agressor percebe a vítima como diferente, como Outro, como estranho, como "fora do padrão", como perigo social que põem em discussão os valores "normais e naturais" defendidos pelo sujeito agressor. Consequentemente, o agressor, ao perceber a vítima como uma ameaça, oriunda de sua diferença, finda por praticar ações que eles caracterizam como crimes de ódio. Por sua vez, nos EUA, por exemplo, o Birô Federal de Investigação (FBI), bem como outras agências federais de segurança e prevenção ao crime, estabelece três elementos de suma importância para a caracterização da ação violenta, como um delito criminal, tipificado como crimes de ódio, a saber:

[...] primeiro, envolve ações que já foram definidas como ilegais em estatutos estaduais ou federais. Assim, a grande maioria das leis de crimes de ódio não criminaliza qualquer novo comportamento; em vez disso, aumentam a penalidade por comportamentos que já são contra a lei. Em segundo lugar, a definição especifica a motivação para cometer a infracção; exige que uma diferença racial, religiosa, étnica ou alguma outra característica que seja diferenciadora da identidade identificada pelo infrator contra a vítima, e que por sua vez, seja motivo para a inspiração do ato criminoso e sua vitimologia. Terceiro, a definição de crimes de ódio aqui apresentada não identifica um conjunto particular de grupos protegidos aos quais a designação de crime de ódio pode ser aplicada exclusivamente. Ao contrário, a legislação penal especial que criminaliza o delito em muitos Estados não inclui qualquer diferença entre o grupo que separa a vítima - grupos raciais, religiosos e étnicos - a mente do ofensor e agressor. (LEVIN e MCDEVITT, 2008, p. 100).

Os autores enfatizam que essa definição enseja contradições e questionamentos sobre a necessidade ou não de padronizar para evitar ambiguidades discursivas na interpretação da tipologia penal, principalmente quando existem casos que não se encaixam diretamente no padrão estabelecido por uma definição genérica:

${ }^{11}$ Em 2008, Levin e Mcdevitt (2008) retomam a discussão sobre os três tipos de agressores de ódio propostos por eles mesmos em 1993, tendo em vista que os autores, ao remontarem os tipos da agressão, findam por edificar uma nova tipologia, que se consagrou nos estudos das infrações penais motivadas, total ou parcialmente, pelo ódio em relação à vítima. 
Este amplo padrão de definição introduz, sem dúvida, alguma ambiguidade na decisão sobre se um caso particular se encaixa ou não, mas também permite a inclusão de casos importantes que podem não surgir com muita frequência; por exemplo, os constantes ataques a pessoas sem-teto que ocorreram, de tempos em tempos, em várias cidades dos Estados Unidos. (LEVIN; MCDEVITT, 2002, p. $103)$.

Do ponto de vista dos autores, é importante que os estudos específicos considerem que a melhor saída seria a possibilidade de uma "padronização aberta", a qual permitiria a inclusão de outros grupos ou de outras ações que possam vir a serem protegidos por uma legislação específica, ou seja, a tipologia dos delitos criminais em matéria de crimes de ódio poderia estar sujeita, para os autores, a uma hermenêutica interpretativa dos processos que produzem a nova retórica jurídica.

Assim, a partir dessas perspectivas, torna-se importante buscar subsídios, nos tratados internacionais e nas legislações nacionais, com objetivo de analisar como estas legislações vêm tratando da temática da violência LGBT, seja a partir de definições ou conceitos materiais sobre estes, criminalizando-os por meio de ordenamentos jurídicos próprios e específicos que façam menção a estes enquanto crimes de ódio. Observa-se que, mesmo ainda sendo insuficientes o número de documentos e de tratados internacionais de direitos humanos que promovam a proteção da população LGBT pelas diferentes formas de violência ser uma realidade, encontramos alguns avanços nas agendas políticas tanto a nível global, quanto a nível regional, de proteção as práticas de ódio motivados pela homofobia, como, por exemplo, a Resolução do Conselho de Direitos Humanos da Organização das Nações Unidas (ONU) de $\mathrm{n}^{\circ}$. A/HRC/17/L.9, quando a Organização Supranacional passou a reconhecer que os direitos LGBT são direitos humanos. ${ }^{12}$

A este respeito, o Conselho da Europa de Direitos Humanos - através da Convenção Europeia de Direitos Humanos -, expressamente consagra proteção da diversidade sexual (orientação sexual e da identidade de gênero) em suas mais distintas formas - a saber: art. $8^{\circ}$

\footnotetext{
${ }^{12}$ Neste sentido, ver a Resolução do Conselho de Direitos Humanos da Organização das Nações Unidas que está disponível em: General Assembly of UN, Human Rights Council. 17th session, follow-up and implementation of de Vienna Declaration. (http://pt.scribd.com/doc/58106434/UN-Resolution-on-Sexual-Orientation-and-GenderIdentity). Acesso em 10/12/2016; e a Conferência Nacional LGBT. Disponível em: http://portal.sdh.gov.br/clientes/sedh/sedh/brasilsem/ANAIS\%20LGBT_final.pdf). Acesso em 10/12/2016. Nesta medida, GORISCH (2013), em O reconhecimento dos Direitos LGBT como Direitos Humanos, apresenta uma aprofundada análise histórica sobre a construção social, política e jurídica do termo LGBT no âmbito internacional de proteção aos direitos humanos.
} 
(Direito ao respeito pela vida privada e familiar), art. $12^{\circ}$ (Direito ao Casamento) e art. $14^{\circ}$ (Proibição de discriminação) - como violações aos princípios universais que resguardam a sexualidade, um dos alicerces da condição humana, e respectivamente, da dignidade da pessoa humana. Desta forma, Dias e Chaves (2012) destacam que a sexualidade é um "direito humano fundamental que acompanha o ser humano desde o seu nascimento, pois decorre de sua própria natureza". Ao passo que recomendam que, como direito de personalidade e do indivíduo, a sexualidade deve ser reconhecida pelas agendas públicas de direitos humanos como "um direito natural, inalienável e imprescritível” (IBID., 201). Dessa feita, as autoras apresentam algumas importantes recomendações da Assembleia Legislativa do Conselho da Europa na Europa - Recomendações $924 / 81^{13}, 1470 / 00^{14}, 1474 / 00^{15}, 1728 / 10^{16}$ e 1915/1017 -, as quais proíbem expressamente nos Estados-membros da Comunidade Europeia à discriminação, a hostilização e o preconceito motivados pela orientação sexual e identidade de gênero. No que concerne à tentativa de outorgar a proteção aos direitos de orientação sexual na territorialidade da Comunidade Europeia, as autoras ressaltam que:

\begin{abstract}
A Assembleia ressalta que a orientação sexual, onde se incluem a bissexualidade, heterossexualidade e homossexualidade, é uma parte profunda da identidade de cada ser humano. A Assembleia também lembra que a homossexualidade foi descriminalizada em todos os Estados-membros do Conselho da Europa. [...] A orientação sexual e identidade de gênero são reconhecidos como motivos de discriminação proibidos. Segundo o Tribunal Europeu dos Direitos Humanos, uma diferença de tratamento é discriminatória se não tiver justificação objetiva e razoável. Sendo a orientação sexual um aspecto mais do que íntimo da vida privada do indivíduo, o Tribunal considera que só razões particularmente graves podem justificar diferenças detratamento baseadas na orientação sexual. (IBID., pp. 203204).
\end{abstract}

Porventura, contata-se aqui que o processo de normativo de proteção à população LGBT, em nível mundial, mesmo encontrando fortes barreiras culturais (político, sociais, religiosas e jurídicas) para a sua institucionalização e consagração, vem conseguindo

13 Recomendação 924 de 1981 - Recomendação 924, de 1981 - relativa à discriminação contra os homossexuais. Disponível em: http://www.assembly.coe.int. Acesso em: 27 de janeiro de 2017

14 Recomendação 1470 de 2000 - relativa à situação dos gays um lésbicas e seus parceiros em matéria de asilo e de imigração nos Estados membros do Conselho da Europa. Disponível em: http://www.assembly.coe.int. Acesso em: 27 de janeiro de 2017.

${ }^{15}$ Recomendação 1474 de 2000 - relativa à situação das lésbicas de e gays nos Estados membros do Conselho da Europa.Disponível em: http://www.assembly.coe.int. Acesso em: 27 de janeiro de 2017.

${ }^{16}$ Recomendação 1728 de 2010 - relativa à discriminação em razão da orientação sexual e identidade de gênero. Disponível em: http://www.assembly.coe.int. Acesso em: 27 de janeiro de 2017.

${ }^{17}$ Recomendação 1915 de 2010 - relativa à discriminação em razão da orientação sexual e identidade de gênero. Disponível em: http://www.assembly.coe.int. Acesso em: 27 de janeiro de 2017. 
importantes conquistas. Principalmente, em nível de legislações e jurisprudências estatais, observa-se que, em muitos Estados soberanos, houve a criminalização tanto da violência motivada pela orientação sexual e identidade de gênero da vítima, quanto do reconhecimento da urgência de políticas públicas de combate aos crimes de ódio em suas distintas formas. Países como os EUA e da Europa Ocidental - Holanda, Suécia, Noruega, Dinamarca, Islândia, Alemanha, Portugal, Espanha entre outros estados - oficializaram em seus estatutos constitucionais ou penais a criminalização e a tentativa de minimização de práticas de violência (crimes de ódio) motivadas pela aversão, discriminação, hostilização e preconceitos a população LGBT.

Neste sentido, Patrícia Gorisch (2013) acrescenta que o Estado brasileiro apresentou, em 18 de dezembro de 2008, durante a celebração dos 60 anos da Carta da Organização dos Estados Americanos (OEA), um projeto de proteção aos direitos humanos que se estendia à orientação sexual e à identidade de gênero, a qual, por sua vez, foi aprovada pelos Estadospartes presentes, passando a se chamar Resolução de Direitos Humanos, Orientação Sexual e Identidade de Gênero (DECLARAÇÃO $\mathrm{n}^{\circ}$. A/63/635/08) ${ }^{18}$; posteriormente, a autora se remete a junho de 2011, quando o Conselho de Direitos Humanos da Organização das Nações Unidas $(\mathrm{ONU})^{19}$ passa oficialmente a se preocupar com a temática da violência LGBT, ou seja, pela violência motivada pelo ódio, motivada pela orientação sexual e pela identidade de gênero da vítima, uma vez que a resolução estabelece em seu artigo primeiro que todos os seres humanos nascem livres e iguais em dignidade e direitos. A Declaração aponta que "O país que não cuidar dos seus cidadãos LGBT, não estará respeitando os Tratados Internacionais de Direitos Humanos e tantos outros documentos internacionais" (IBID., p. 7).

18 Neste sentido, ver Declaração nº. A/63/635/08 - Declaração de Direitos Humanos, Orientação Sexual e Identidade de Gênero. Disponível em: http://www.abglt.org.br/port/declaracao_conjunta_63_635.html. Acesso em 03 de janeiro de 2017.

19 De acordo com a Declaração Pública da Anistia Internacional, em 11 de dezembro de 2008, durante as comemorações do $60^{\circ}$ aniversário da Declaração dos Direitos Humanos (DUDH), a Assembleia Geral das Nações Unidas abordou, pela primeira vez, e formalmente oficializou a promessa de elaborar uma Declaração que combata e previna as violações de direitos humanos motivados pela orientação sexual e pela a identidade de gênero. Entre os países que se comprometeram a participar do processo de elaboração desta Declaração, que deveria entender os direitos humanos a todos, estão nações dos quatro continentes, entre estas: Argentina, Brasil, Croácia, França, Gabão, Japão, Países Baixos e Noruega. A leitura da Declaração será a primeira vez que a Assembleia Geral abordou formalmente as violações dos direitos baseadas na orientação identidade de gênero. Mais a respeito ver: United Nations: General Assembly to Address Sexual Orientation and Gender Identity Statement affirms promise of Universal Declaration of Human Rights. In. Amnesty International. Disponível em: United Nations: General assembly to address sexual orientation and gender identity - Statement affirms promise of Universal Declaration of Human Rights. Disponível em: (http://www.amnestyusa.org/document.php?id=ENGIOR410452008); http://www.amnestyusa.org/document.php?id=ENGIOR410452008. Acesso em: 03 de janeiro de 2017. 
Apesar do exposto, é importante considerar que inexiste uma regulamentação universal ou um tratado internacional que, oficialmente, proteja os direitos humanos em matéria de orientação sexual e identidade de gênero, da mesma forma que inexiste ainda padronizações conceituais sobre os crimes de ódio e, respectivamente, sobre a homofobia, tendo em vista que a matéria vem sendo tratada, diante de sua especificidade, em total dependência com os ordenamentos jurídicos do direito interno estatal, que incorporaram as normas e os tratados internacionais de proteção a sujeitos LGBT em seus ordenamentos próprios.

\section{Articulando os Processos Argumentativos que Incidem sobre os Discursos do Ódio Homofóbico}

Os processos argumentativos que incidem sobre o fenômeno do preconceito contra pessoas que possuem uma etnia, raça, religião, orientação sexual diferente da maioria não é um fenômeno social novo. De modo que a análise sobre a história das sociedades humanas é uma análise repleta por "conflitos intergrupais" (JENNESS; GRATTET, 2001), que levaram a tragédias e massacres genocidas pela ausência de mecanismos de negociação política e de políticas públicas inclusivas (MELO, 2001). Neste contexto, ações de ódio tem sido parte do desenvolvimento da própria humanidade, assim, eclodiam ações de ódio, desprovidas de respeito à alteridade, as quais tinham como estratégias não apenas a dominação ou a submissão de grupos ou comunidades conquistadas, mas também a sua total aniquilação, em virtude de serem considerados inimigos ou detentores de atributos ou peculiaridades (culturais e religiosas) estranhas ao grupo ou estado agressor (ZAFFARONI, 2014b, p. 17).

Análises sobre políticas internas de governança comprovam que, ao longo da história, os Estados agiam de forma diferente na prevenção e propagação do ódio em suas linhas de frente. Países ocidentais (como os EUA e os países da União Europeia) vêm institucionalizando políticas públicas e legislações específicas contra a propagação do crime de ódio nos mais diferentes âmbitos de suas sociedades, demonstrando a preocupação em tratar o ódio como questão de saúde pública e como objeto de perseguição pelo sistema de justiça criminal. Da mesma forma, verifica-se que, no contexto político da América Latina, a temática do ódio motivado pelo preconceito é uma realidade indiscutível, que se fez e ainda se 
faz presente, desde a instauração pelas metrópoles europeias e suas políticas de colonização com uso do discurso legitimador da moralidade civilizatória de matriz judaico-cristã.

A análise de causa do preconceito com o estranho e com o diferente é baseada no axioma de que as pessoas têm a capacidade de formar e, consequentemente, de desenvolver preconceitos e estereótipos sobre o "outro" pela aprendizagem, pela observação ou por práticas de repetição. O que se leva a apontar que estas atitudes, que não são originárias da espécie humana, mas que são socialmente adquiridas a partir do processo de socialização. (GREEN, 2000).

O fato é que em algumas culturas ou processo de socialização, a hostilização, a estigmatização, a rotulação e o preconceito têm sido estimulados nos Estados nacionais por mecanismos de educação. Assim, o preconceito e a discriminação ao Outro se desenvolve influenciado pela vivência e por diferentes processos travados no dia a dia, onde o ódio e o amor caminham juntos na proposição da razão e da emoção (IBID., p.12). Jack Levin e Jack McDevitt percebem, em consequência, que o preconceito é resultado da ausência da consciência de alteridade, ou pela negação a identificação de pertença do "outro" (IBID., 1993, p. 27). Percebe-se que os vínculos sociais se dão a partir da educação e, como resultado, por repetições ativas que buscam não apenas externalizar o ódio contra o "Outro", visando o seu aniquilamento ou a sua repulsa, como também a internalização neste "Outro" de que a sua diferença é uma ameaça à harmonia do agrupamento social (internalização da rejeição social por práticas homofóbicas).

Sabine Hark (20o, p. 29) acrescenta que uma "sólida identidade social de um grupo em específico poderá não apenas influenciar a autoestima individual dos indivíduos dentro deste mesmo grupo", como também poderá ser determinante na edificação de uma identidade capaz de promover positivas interações intergrupais de aprendizagem, mesmo que com indivíduos pertencentes a grupos diferentes. Isso acontecerá sempre que um grupo não exclui a possibilidade de seus membros interagirem socialmente com membros de outros grupos, mesmo que inexista uma identificação (outsiders). Decerto, e a este respeito, já existe ampla literatura produzida sobre a homofobia, desde que o psicólogo estadunidense George Weinberg cunhou o termo, no auge do debate político das movimentações político-ativistas e intelecto-acadêmicas nas últimas décadas do século XX, pela primeira vez. (MOTT, 1997). Dessa forma, em 1972, a partir da etimologia das palavras, homo e fobia, Weinberg se apropria dos termos e cria a palavra homofobia, que indicaria o ódio, a aversão, a hostilidade, 
o medo e demais valores sociais que renegam a orientação sexual entre duas pessoas do mesmo sexo, ou seja, que não se enquadre no comportamento heterossexual dominante. ${ }^{20}$ Desta forma, Borillo (2010) complementa a perspectiva de Weinberg, quando caracteriza a homofobia como:

\begin{abstract}
A hostilidade geral, psicológica e social contra aquelas e aqueles que, supostamente, sentem desejo ou têm práticas sexuais com indivíduos de seu próprio sexo. Forma específica do sexismo, a homofobia rejeita, igualmente, todos aqueles que não se conformam com o papel predeterminado para seu sexo biológico. Construção ideológica que consiste na promoção constante de uma forma de sexualidade (hétero) e detrimento de outra (homo), a homofobia organiza uma hierarquização das sexualidades e, dessa postura, extrai consequências políticas. (IBID., p. 34).
\end{abstract}

Nessa perspectiva, o autor considera que a denúncia das práticas homofóbicas é um mecanismo eficiente na prevenção e no combate a atitudes hostis direcionadas a indivíduos homossexuais. Borillo, pois, tem o mérito de relacionar a homofobia com outras formas de discriminação, de preconceito e de estigmatização demonstra a vulnerabilidade social que atinge a vida dos indivíduos LGBT, devido à desqualificação, à marginalização e à estranheza em que o desejo e as relações sexo-afetivas, entre pessoas do mesmo sexo, são socialmente propagados. (IBID, 2010, p. 13). Além disso, o autor defende que políticas públicas inclusivas e ações afirmativas poderiam vir a ter resultados positivos, se estas objetivarem a promoção de discussões e a educação para a diversidade, edificando e deslegitimando práticas e estratégias propagadoras da indiferença e da exclusão social, desenraizando, portanto, os sustentáculos teóricos de uma histórica cultura falocêntrica, heteronormativas e patriarcal - e, diga-se de passagem: heteromasculina -, que alimentam as práticas ideológicas em torno da homofobia.

\footnotetext{
${ }^{20}$ George Weinberg parte da afirmação de que a homofobia seria influenciada, por um lado, por questões religiosas; ademais, o autor acredita que o temor da própria homossexualidade elevaria as chances de práticas homofóbicas pelo agressor; em terceiro lugar, a inveja reprimida em relação à vítima levaria à externalização de práticas homofóbicas; em quarto lugar, Weinberg sugere que a simples presunção da homossexualidade representaria uma ameaça aos valores pessoais, morais e culturais estabelecidos; por fim, o autor faz referência à questão da imortalidade substituta, que seria resultado da própria decência por prole, questão superada no hodierno contexto cultural das sociedades civilizadas. Instigante ressaltar que as limitações das perspectivas ressaltadas por Weinberg, se dão, principalmente, pelo cunho psicologizante e estruturalista de sua reflexão, o que vai de encontro à perspectiva interacionista e (des) construtivista que alicerça o presente ensaio. (WEINBERG, 1977).
} 


\section{Considerações Finais}

A partir deste ensaio constamos que a argumentação em discursos contra a homofobia percebe-a como um fenômeno social com reverberações psicológicas que geram condutas e ações que apresentam nuances em forma de violência - assim como o racismo, a xenofobia, o classismo e a intolerância religiosa - que se tornam, às vezes, difíceis de serem percebidos. Dentro desta linha de pensamento, apontam os discursos analisados que a lógica da dominação parte da absorção do discurso heterossexista que, embora proclame, em alguns casos, a adoção do princípio da igualdade formal, não consegue inserir no seu aparato jurídico, a materialidade da criminalização, ou seja, a proteção legal é existente em alguns Estados, como no Estado brasileiro, todavia, a discriminação é dissimulada por diferentes práticas que partindo da naturalidade da heterossexualidade, tendem a descaracterizar (desvalorizar e desnaturalizar) outras sexualidades que não correspondem ao modelo reservado pelo grupo dominante.

É importante destacar que estes argumentos findam por dissimular a falsa ideia de proteção geral pelo Estado Democrático de Direito, o qual em situações especificas por estar ausente, finda por contribuir com a produção e proliferação de casos isolados de ações homofóbicas no cotidiano social. Devido à ausência de proteção jurídica específica ou especial contra o ódio, visando diminuir a vulnerabilidade social da população LGBT no nosso Estado. Em adição a isto, tanto os discursos acadêmicos, quanto os militantes apontam que as causas da homofobia têm raízes na complexidade dos fenômenos psicológicos e sociais fundamentados em estruturas que idealizam em nível de organização social a heterossexualidade como norma universal, tanto no plano sexual como afetivo.

Os discursos que constituem as vozes gestoras e receptoras dos dispositivos da discriminação homofóbica, findam por impedir a promoção e o reconhecimento da igualdade entre sujeitos em uma sociedade heterogênea, a qual é direcionada pelos paradigmas da socialização heterossexista, os quais legitimam em diferentes contextos do cotidiano social, situações de desigualdade de direitos. Principalmente, em contextos sociais que diferenciam o outro que não corresponde às expectativas da lógica binária dos gêneros, geradas pelo simbolismo cultural e coletivo que naturaliza a heterossexualidade. Neste contexto, percebemos a partir dos argumentos em discursos da militância e da academia que defendem a criminalização dos crimes de ódio homofóbico que o sujeito agressor é capaz não apenas de 
desprezar o Outro por sua diferença, mas também de dispor ou de fazer uso de mecanismos capazes de silenciar e distanciar este Outro da essência dos Direitos e Garantias Fundamentais ao Ser Humano. Por conta disso, o sujeito homofóbico não percebe a diferença entre o sexo e o gênero, muito menos a possibilidade de se sensibilizar com a existência de outras identidades de gênero, capazes de recriar os corpos, além das socialmente estabelecidas.

Finalmente, consideramos que a socialização dos papéis sociais (papeis sexuais), ao mesmo tempo em que orienta e normatiza a sexualidade para o binarismo heterossexual como natural (hétero-naturalidade), universal (hétero-universalidade) e normal (héteronormalidade), também promove a exclusão social, promovendo a desintegração social e, por conseguinte, a rotulação social e a etiquetagem de desviante, a partir de práticas de violência, que aqui chamamos de violência homofóbica, atingindo toda uma população de indivíduos com orientação sexual não heterossexual.

Observamos que os argumentos em discursos e em diferentes contextos trazem atos da fala militante que criticam a não criminalização da homofobia, bem como a ausência de políticas públicas preventivas (ostensivas e repressivas), como um todo, enfatizam que tais práticas findam por legitimar e justificar a repressão da homossexualidade, em uma sociedade que se fundamenta nos princípios do bem-estar social e no da dignidade da pessoa humana. Por isso, observa-se nas linguagens entre os diferentes discursos existentes, acadêmico e militante, o posicionamento ideológico que se propõem a articular o discurso justificador da homofobia com a ameaça à supremacia da heterossexualidade pela população LGBT.

\section{Referências}

BERSON, Betty. Setting them straight: you can do something about bigotry and homophobia in yor life. New York: Penguin Books USA, 1996.

BERUTTI, Eliane Borges. Gays, Lésbicas, transgenders: o caminho do arco-íris na cultura norteamericana. Rio de Janeiro: EdUERJ, 2010.

BORRILLO, Daniel. Homofobia. História e crítica de um preconceito. Tradução de Guilherme João de Freitas Teixeira. Belo Horizonte: Autêntica, 2010.

BÖS, Mathias. Rasse und Ethnizität. Zur Problememgeschichte zweier Begriffe in der amerikanischen Soziologie. Auflage Juni. VS Verlag für Sozialwissenschaften. Wiesbaden: GWV Fachverlag, 2005. 
BOYLE, Kelvin. Hate Speech: the United Staates versus the rest of the world? Heinonline, Maine Law Review, v. 53, n. 2, 2001.

BRAYNER, Aquiles. Lampião um bandido social? Análise discursiva da Revista Lampião da Esquina. 1998. 115f. Dissertação (Mestrado em História) - Universidade de Leiden, Leiden, 1998.

BUTLER, Judith. Problemas de gênero: feminismo e subversão da identidade. Tradução Renato Aguiar. 2. ed. Rio de Janeiro: Civilização Brasileira, 2008.

CARRARA, Sérgio. Políticas e direitos sexuais no Brasil contemporâneo. BAGOAS, n. 05, 2010, p. 131-147. Disponível em: <http://www.cchla.ufrn.br/bagoas/v04n05art08_carrara.pdf>. Acesso em: 16 set. 2015.

DIAS, Maria Berenice; CHAVES, Marianna. Diversidade sexual na Europa - uma visão a partir da Jurisprudência do Tribunal Europeu dos Direitos Humanos. In: GONÇALVES, Cláudia Maria da Costa. Direitos humanos: direitos de quem? Curitiba: Juruá, 2012. p. 201-224.

FACCHINI, Regina. Facchini. Sopa de letrinhas? Movimento homossexual e produção de identidades coletivas nos anos 90. Rio de Janeiro: Garamond, 2005.

. Movimento homossexual no Brasil: recompondo um histórico. Cad. AEL, [S.1.], v. 10, n. 18/19, 2003. Disponivel em: <http://www.academia.edu/3038398/Movimento_homossexual_no_Brasil_recompondo_um_hist\%C3 \%B3rico>. Acesso em: 16 out. 2013.

FRANKLIN, John Hope; MOSS Jr., Alfred A. Von der Sklaverei zur Freiheit. Die Gechichte der Schwarzen in den USA. Übersetzung Angela Adams. Berlin: Ullstein, 1999.

GORISCH, Patrícia Cristina Vasques de Souza. O reconhecimento dos Direitos LGBT como Direitos Humanos. 2013. 115f. Dissertação (Mestrado em Direito Internacional) - Universidade Católica de Santos, Santos, 2013.

GREEN, James N. Além do Carnaval: a homossexualidade no Brasil do século XX. São Paulo: UNESP, 2000.

HALL, Stuart. Da diáspora: identidades e mediações culturais. Tradução Adelaine la Guardia Resende. Belo Horizonte: UFMG, 2003.

HARK, Sabine. Durchquerung des Rechts Paradoxien einer Politik der Rechte. In: BERGER, Nico J.; HARK, Sabine; ENGEL, Antke; GENSCHEL, Corinna (Hg.). Queering Demokratie sexuelle politiken. Berlin: Querverlag, 2000, s. 28-44.

JENESS, Valeria; GRATTET, Ryken. Criminology. Examining the Boundaries of Hate Crime Law: Disabilities and the "Dilemma of Difference". The Journal of Criminal Law \& Criminology., Northwestern University, v. 91, n. 3, p. 653-697, 2001a,

LAURENTIS, Teresa de. The technology of gender. Indiana: Indiana Universtity Press, pp. 1-30. 1987. Disponível em: 〈http://marcoaureliosc.com.br/cineantropo/lauretis.pdf>. Acesso em: 18 mar. 2015. 
LEVIN, Jack; MCDEVITT, Jack. Hate Crimes. Encyclopedia of Peace, Violence, and Conflict., Northeastern University: Academic Press, v. 2, p. 1-25, 2008.

Session C. Bias Crime Offenders. Responding to Hate Crime: A Multidisciplinary Curriculum, p. 47-88. In: National Center for Hate Crime Prevention. 1993. Disponível em: <https://www.kirkusreviews.com/book-reviews/jack-levin/hate-crimes/ >. Acesso em: 07 nov. 2014.

Hate crimes: The rising tide of bigotry and bloodshed. New York: Plenum, 2002.

LOURO, Guacira Lopes. Teoria Queer - uma política pós-identitária para a educação. Estudos Feministas, v. 2, Ano 9, p. 541-553. 2001, Disponível em: <http://www.scielo.br/pdf/ref/v9n2/8639.pdf>. Acesso em: 13 abr. 2015.

MACRAE, Edward. Em defesa do Gueto. Novos Estudos Cebrap, São Paulo, v. 2, n. 1, abr. 1983. p. 53-60. Disponível em: <www.giesp.ffch.ufba.br>. Acesso em: 13 abr. 2015.

MELO, Miguel A. S. De. Representações Sociais da Violência contra Homossexuais no Judiciário: Um estudo de caso de crime de ódio homofóbico no Estado do Ceará. 305 p. Tese (Doutorado em Sociologia) Programa de Pós-graduação em Sociologia, Universidade Federal de Pernambuco, Centro de Filosofia e Ciências Humanas. Recife, 2017.

,. Die Menschenrechtsverletzugen durch Hassverberchen. Eine Analyse der homophoben Gewalt am Beispiel Brasiliens. 2001, 189f. Dissertação (Mestrado em Ciências Sociais), Universität Hamburg, Hamburg, 2001.

MOTT, Luiz Roberto de Barros. Homofobia: a violação dos direitos humanos dos gays, lésbicas e travestis no Brasil. San Francisco: IGLRHC; Salvador: GGB, 1997.

Dez viados em questão: Tipologia dos homossexuais na cidade de Salvador. Salvador: Espaço Bleff, 1987.

1986.

O sexo proibido: Virgens, gays e escravos nas garras da inquisição. São Paulo: Papirus,

FRY, Peter; MACRAE, Edward. O que é homossexualidade. 3. ed. São Paulo: Brasiliense, 1988. (Coleção Primeiros passos).

RIOS, Roger Raupp. O conceito de homofobia na perspectiva dos direitos humanos e no contexto dos estudos sobre o preconceito e discriminaçãoIn : POCAHY, Fernando (Org.).

Rompendo o silêncio: Homofobia e heterossexismo na sociedade comtemporânea. Porto Alegre: Nuances, 2007. p. 27-48.

ROSENFELD, Michel. Hate Speech in Constitutional Jurisprudence: a comparative analysis. Cardozo Law Review, New York, 24, n. 4, abril 2003, p. 2. Disponível em: $<$ http://internationalhumanrightslaw.net/wp-content/uploads/2011/01/Hate-Speech-in-ConstitutionalJurisprudence-A-Comparative-Analysis.pdf $>$. Acesso em: 14 abr. 2016.

RÄTHZEL, Norbert. Gegenbilder. Nationale Identität durch Konstruktion des anderen. Berlin: Opladen, 1997. 
SANTOS, Rick J. PoÉtica da diferença: um olhar queer. São Paulo: Fantash, 2014.

SANTOS, Boaventura de Sousa. Pela Mão de Alice: o social e o político na Pós-Modernidade. 12. ed. São Paulo: Cortez, 2008.

\begin{tabular}{ccccc}
\multicolumn{2}{c}{ Para uma sociologia das ausências e uma sociologia das emergências. Revista Crítica de } \\
Ciências $\quad$ Sociais, $[$ S.1], $\quad 63, \quad$ p. 237-280, 2002. Disponível em:
\end{tabular} 〈http://www.boaventuradesousasantos.pt/media/pdfs/Sociologia_das_ausencias_RCCS63.PDF $\rangle$.

Acesso em: 15 nov. 2015.

SILVA, Claudio Roberto da. Reinventando o sonho. História oral da vida política e homossexualidade no Brasil Contemporâneo. 1998. 156f. Dissertação (Mestrado em História Social) - Faculdade de Filosofia, Letras e Ciências Humanas, Universidade de São Paulo, São Paulo, 1998.

SILVA, Tomaz Tadeu da. A produção social da identidade e da diferença. In: Tomaz Tadeu da Silva (Org.). Identidade e diferença: a perspectiva dos estudos coloniais. 10. ed. Petrópolis, RJ: Vozes, 2011.

(Org.). Pedagogia dos monstros: os prazeres e os perigos da confusão de fronteiras. Belo Horizonte: Autêntica, 2000. p. 23-60.

SPAGHOL, Antônio Sérgio. O desejo marginal. Violência contra homossexuais na cidade de São Paulo. 1996. 156f. Dissertação (Mestrado em Ciências Sociais) - Universidade de São Paulo, São Paulo, 1996.

TREVISAN, João Silvério. Devassos no paraíso. São Paulo: Limonard, 1986.

WEINBERG, George. La Homosexualidad Sin Prejuicios: Un revolucionário enfoque psicológico. Traducción de Martha Mastrogiácomo Society and the Healthy Homosexual, 1972. Cubierta Carlos Roland. 2. ed. Colección Liberd y Cambio. Buenos Aires, Barcelona: Granica Editor, 1977.

WOODWARD, Kathryn. Identidade e diferença: uma introdução teórica e conceitual. p 7-72.. In: SILVA, Tomaz Tadeu da (Org.). Identidade e diferença: a perspectiva dos estudos coloniais. 10. ed. Petrópolis, RJ: Vozes, 2011.

ZAFFARONI, Raul Eugênio. O inimigo no direito penal. Tradução Sérgio Lamarão. Rio de Janeiro: Revan, 2014b. (Pensamento Criminológico).

Como citar este artigo (Formato ABNT):

MELO, Miguel A. S. de; SILVA, Isaac de O. M e; DIAS, Karollyne M.; GOMES FILHO, Antoniel dos S. G. A Homofobia como Signo Ideológico dos Crimes de Ódio: Uma Análise da Argumentação Discursiva sobre os Direitos LGBT'S. Id on Line Revista Multidisciplinar e de Psicologia, 2017, vol.11, n.38, p. 57-79. ISSN: 1981-1179.

Recebido: 29.09.2017

Aceito: 09.11.2017 